\title{
Poster \\ Bone augmentation with Xenograft may not influence on implant stability - in vivo study in sheep
}

No:003

1. Department of periodontology, School of graduate dentistry, Rambam health care campus, Haifa, Israel.

2. Laboratory for hard tissue regeneration, CRIR institute, Rambam health care campus.

3. Faculty of Medicine, Technion - Israeli Institute of Technology, Haifa, Israel.

\section{Abstract}

\section{Background:}

Initial implant stability during placement is important for implant survival. It depends mainly on the amount and quality of the bone. Xenograft has become a popular grafting material for socket preservation aimed at reducing volumetric changes of the bone following tooth extraction.

Aim

To compare bone quantity and primary implant stability two months following treatment of surgically created bone defects using two different types of xenografts.

Materials and Methods:

Eighteen artificial bone defects were prepared in the mandible of four sheep using conventional drilling burs (Ø5mm and $8 \mathrm{~mm}$ length) under saline irrigation. Defects were randomly grafted with xenografts: Bio-Oss $(\mathrm{BO})$ or Bioactive Bone (BB) or left for spontaneous healing (control) (6 defects in each group). Following 8 weeks, a bone biopsy was harvested using a trephine drill of (add diameter) following by the installation of NEO dental implants. During installation, the peak insertion torque (IT) was measured by calibrated hand ratchet and primary stability was measured using the Osstell system.

Results:

Histomorphometric analysis showed a higher percentage of new bone formation in the natural healing defects compared to sites with xenograft $(68.66 \pm 4.5 \%, 48.75 \pm 4.34 \%$ $50.33 \pm 4.0 \%$ control, $\mathrm{BB}, \mathrm{BO}$ respectively). Connective tissue portion was higher in the $\mathrm{BO}$ and $\mathrm{BB}$ groups compared to control $(44.25 \pm 2.98 \%, 41 \pm 6 \%$ and $31.33 \pm 4.5$ $\mathrm{p}<0.05)$. Residual grafting material was similar in $\mathrm{BO}$ and $\mathrm{BB}(7 \pm 2.44 \%, 8.66 \pm 2.1 \%)$. The mean IT (C $36.6 \pm 13.7$, BO $40.8 \pm 16.9$, BB $37.5 \pm 10.7, p>0.05)$ and ISQ (C $60.8 \pm$ 10.6, BO $64.3 \pm 15.6$, BB $62.3 \pm 12.6$ ) values were statistically similar between 3 groups of the study. A positive correlation was found between IT and ISQ $(r=0.65, P=0.00)$

\section{Conclusions:}

Implant's primary stability was not influenced by the type of the xenograft used in the study at delayed implant placement approach. These results may be attributed to a relatively high bone fill of the defect $(\sim 50 \%)$ two months after grafting.

\section{Background and Aim}

The use of dental implants for the rehabilitation of missing teeth is an acceptable and promising treatment option. ${ }^{1}$ However, the use of implants may be limited if the amount and volume of the alveolar bone are poor.

Techniques for ridge preservation have been successfully tested in clinical trials using bone substitutes from different. ${ }^{2}$

A xenograft is one of the factors that may contribute to preserving ridge dimensions. One of the criteria for installing implants is the initial stability obtained during the procedure. Stability depends on several factors. Among them is the type of bone.

This animal study aims to examine and compare bone quantity and primary implant stability two months following socket preservation using two types of xenogeneic materials.

\section{Results}

Fig 1: First and second surgical interventions
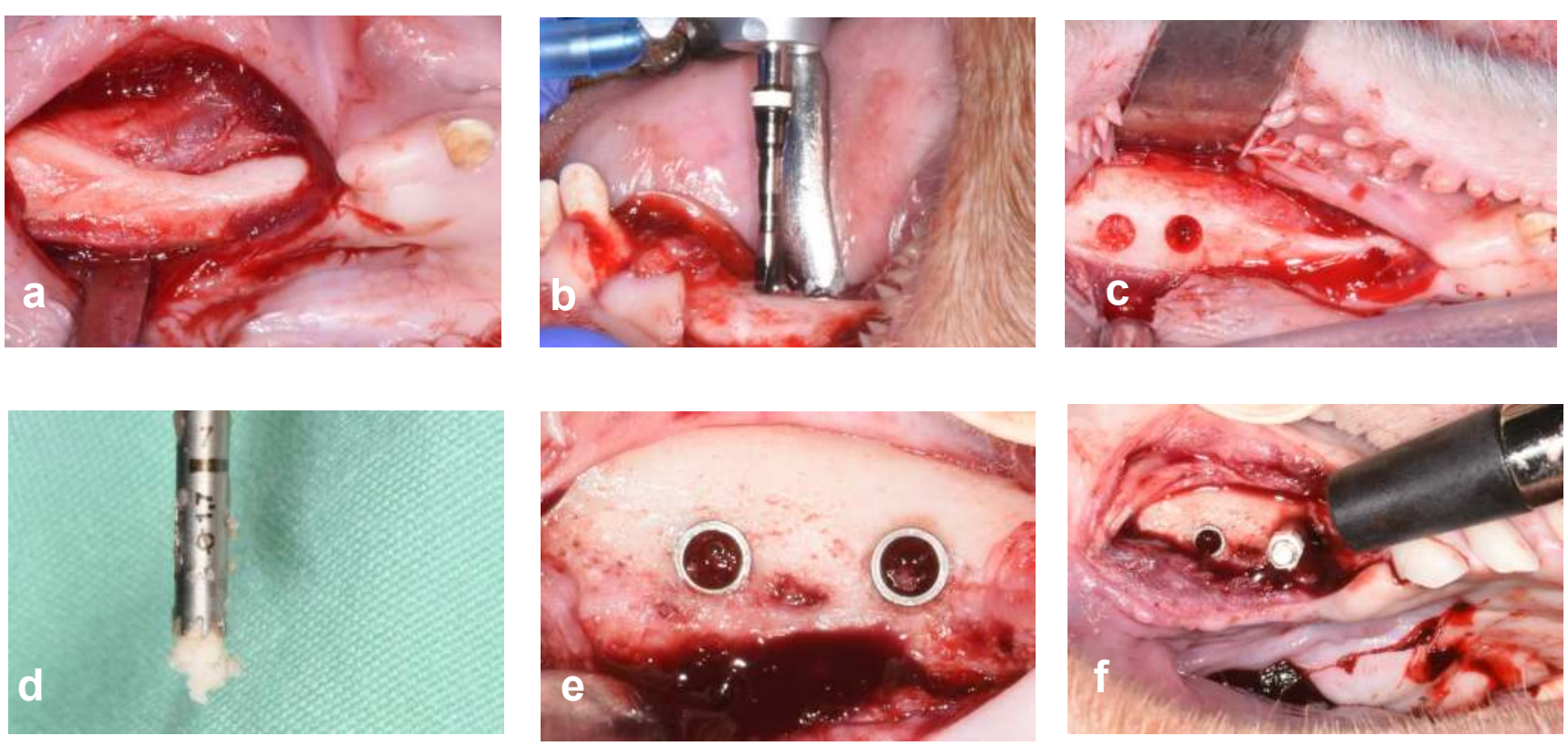

Table 1: Histomorphometric analysis (\% total sample area, mean \pm SD), Bioactive Bone (BB) Bio-Oss (BO).

\begin{tabular}{|l|c|c|c|}
\multicolumn{1}{r}{ Group } & \% Bone & $\%$ Connective tissue & \% Residual graft \\
\hline BB & $48.75 \pm 4.34 \%^{*},{ }^{* *}$ & $44.25 \pm 2.98 \%{ }^{*},{ }^{* *}$ & $7 \pm 2.44 \%{ }^{*}$ \\
\hline BO & $50.33 \pm 4.0 \% \ddagger,{ }^{*}$ & $41 \pm 6 \% \neq,{ }^{*}$ & $8.66 \pm 2.1 \%{ }^{*}$ \\
\hline Control & $68.66 \pm 4.5 \%{ }^{* *}, \ddagger$ & $31.33 \pm 4.5 \% \ddagger,{ }^{* *}$ & - \\
\hline
\end{tabular}

${ }^{*}$ BB-BO $p>0.05,{ }^{* *}$ BB-C $p<0.05, \ddagger B O-C p<0.05$

Table 2: Insertion Torque ( $\mathrm{N} / \mathrm{cm}$ ) and ISQ values (mean $\pm \mathrm{SD}$ ) Bioactive Bone (BB), Bio-Oss (BO).

\begin{tabular}{l|c|c|c|} 
Group & Insertion Torque & ISQ & $\begin{array}{l}\text { Fig 2: Representative figures of each } \\
\text { group. (a) BioActive bone (b) BioOss }\end{array}$ \\
\hline BB & $37.5 \pm 10.7^{*},{ }^{* *}$ & $62.3 \pm 12.6{ }^{*},{ }^{* *}$ \\
\hline BO & $40.8 \pm 16.9 \pm,{ }^{*}$ & $64.3 \pm 15.6 \pm,{ }^{*}$ \\
Control & $36.6 \pm 13.7^{* *}, \pm$ & $60.8 \pm 10.6 \pm,{ }^{* *}$ \\
\hline issue
\end{tabular}

*BB-BO $p>0.05,{ }^{* *}$ BB-C $p>0.5, \ddagger$ BO-C $p>0.05$ 